\title{
ESTABELECIMENTO E MULTIPLICAÇÃO IN VITRO DE PRUNUS sp. EM DIFERENTES MEIOS DE CULTIVO ${ }^{1}$
}

\author{
ALEXANDRE COUTO RODRIGUES², CARLOS AUGUSTO POSSER SILVEIRA³, GÉRSON RENAN DE LUCES \\ FORTES ${ }^{4}$, JOSÉ CARLOS FACHINELLO ${ }^{5}$, JOÃO BAPTISTA DA SILVA ${ }^{6}$
}

\begin{abstract}
RESUMO: O trabalho foi realizado com o objetivo de avaliar diferentes meios de cultivo no estabelecimento e multiplicação in vitro de espécies do gênero Prunus. Os segmentos nodais de $1,0 \mathrm{~cm}$ foram mantidos sob luz fluorescente com radiação de $20 \mathrm{mE} . \mathrm{m}^{-2} . \mathrm{s}^{-1}$, fotoperíodo de 16 horas e temperatura de $25 \pm 2^{\circ} \mathrm{C}$. No estabelecimento, testaram os meios MS, MS 3/4, SH e Villegas, e na multiplicação: SH e MS 3/4. O meio MS 3/4 foi testado em diferentes concentrações de ágar $\left(4,5 ; 5,5 ; 6,5\right.$ g. $\left.\mathrm{L}^{-1}\right)$ Avaliaram-se as percentagens de estabelecimento dos explantes, contaminação, oxidação e segmentos não brotados. O meio Villegas apresentou menor oxidação durante o período de estabelecimento in vitro. Com o meio MS 3/4, verificou-se maior percentagem de estabelecimento dos explantes. Na fase de multiplicação, avaliaram-se a percentagem de crescimento, a taxa de multiplicação e o número de brotações. O meio MS 3/4, com 5,5 g.L.-1 de ágar, apresentou os melhores resultados.
\end{abstract}

Termos para indexação: Pessegueiro, ameixeira, micropropagação.

\section{ESTABLISHMENT AND MULTIPLICATION IN VITRO OF PRUNUS sp. IN DIFFERENT CULTURE MEDIA}

Abstract: The work was performed aiming to evaluate different media for the establishment and in vitro multiplication of some rootstocks species of Prunus. Microcutings of 1,0 cm long were incubated under $20 \mathrm{mE} \cdot \mathrm{m}^{-2} \cdot \mathrm{s}^{-1}$ radiation provided by white fluorescent lamps, 16-hour photoperiod and temperature of $25 \pm 2^{\circ} \mathrm{C}$. The establishment media used were as follow: MS, $3 / 4 \mathrm{MS}$, SH and Villegas, and the multiplication media used were: SH and $3 / 4$ MS. The $3 / 4$ MS medium was also tested with different agar concentrations $\left(4.5 ; 5.5 ; 6.5\right.$ g. $\left.\mathrm{L}^{-1}\right)$. The percentage of establishment, contamination, oxidation and growing of the explants were evaluated. The Villegas medium provided low oxidation during the period of $i n$ vitro establishment. The $3 / 4 \mathrm{MS}$ medium provided higher percentage of establishment of explants. In the multiplication phase, the highest growth percentage, multiplication rate and bud number, were found in $3 / 4 \mathrm{MS}$ medium with $5.5 \mathrm{~g} . \mathrm{L}^{-1}$ agar.

Index terms: peach, plum, micropropagation.

\section{INTRODUÇÃO}

O uso de mudas com qualidade sanitária e genética é de fundamental importância na implantação de um pomar comercial. No Sul do Brasil, os porta-enxertos de frutíferas de caroço são propagados por sementes. Porém, nem sempre se conseguem sementes em quantidade e qualidade para satisfazer as necessidades. Portanto, para atender a essa demanda, é interessante o uso da micropropagação. Esta técnica envolve o uso de diferentes meios de cultura que variam de acordo com a espécie, com a cultivar que se deseja trabalhar e, também com o estádio de desenvolvimento da planta (Grattapaglia \& Machado, 1998). Com o gênero Prunus, vários trabalhos, com os mais diferentes objetivos, têm sido realizados nos últimos anos (Theriou, 1998; Loreti \& Massai, 1995; Morini et al.,1990). Theriou (1998), utilizou o meio MS para a multiplicação do porta-enxerto $\mathrm{Mr}$.S 2/5, com adição de cloreto de sódio $\left(\mathrm{NaCl}_{2}\right)$ ou cloreto de cálcio $\left(\mathrm{CaCl}_{2}\right)$ ao meio, e concluiu que a presença desses sais incrementa a produção in vitro. Morini et al. (1990), também testaram o meio MS para a multiplicação dos porta-enxertos Mr.S 2/5 e GF 677 , obtendo bons resultados. Apesar disso, esta técnica, quando aplicada em espécies do gênero Prunus, apresenta alguns problemas, tais como oxidação e contaminação dos explantes durante a fase de estabelecimento e também pequena taxa de desenvolvimento durante a fase de multiplicação, necessitando mais estudos. O presente trabalho teve por objetivo avaliar o estabelecimento e a multiplicação de cultivares de Prunus sp., em diferentes meios de cultura.

\section{MATERIAL E MÉTODOS}

O trabalho foi realizado no Laboratório de Cultura de Tecidos da Embrapa Clima Temperado, Pelotas-RS.
Experimento I: Fase de estabelecimento

As cultivares estudadas na fase de estabelecimento in vitro foram os porta-enxertos: Marianna Comum, GF677, Aldrighi, Okinawa, Nemaguard, Mirabolano e as cultivares-copa: Eldorado, Diamante e Santa Rosa. Os meios de cultura MS (Murashige \& Skoog, 1962), MS 3/4, V (Villegas et al., 1992) e SH (Schenck \& Hildebrandt, 1972) foram utilizados para o estabelecimento dos explantes. Aos sais de macro e micronutrientes e vitaminas dos meios citados, foram adicionados AIB $\left(0,01 \mathrm{mg} . \mathrm{L}^{-1}\right)$ e BAP $\left(0,7 \mathrm{mg} \cdot \mathrm{L}^{-1}\right)$. Os meios foram acrescidos de sacarose (30 g.L $\left.\mathrm{L}^{-1}\right)$, ágar (6,5 g.L $\left.\mathrm{L}^{-1}\right)$, mioinositol (100 mg.L $\left.\mathrm{L}^{-1}\right)$, ácido ascórbico (10 mg. $\left.\mathrm{L}^{-1}\right)$, tiamina $\left(1,0 \mathrm{mg} . \mathrm{L}^{-1}\right)$ e o $\mathrm{pH}$ foi ajustado para 5,8 .

Os ramos das diferentes cultivares foram pulverizados a cada dois dias com Benomil (1,0 mg.L $\left.\mathrm{L}^{-1}\right)$ e Agrimicina (2,4 mg. $\left.\mathrm{L}^{-1}\right)$, por duas semanas, para a desinfestação dos mesmos. Na coleta das brotações terminais (dezembro), as plantas estavam em desenvolvimento vegetativo. No laboratório, fez-se a desinfestação com álcool etílico 70\% por 10 segundos, seguida de tratamento em solução de hipoclorito de sódio a 1,5\%, adicionada de uma gota de tween, onde os ramos permaneceram imersos durante 15 a 20 minutos. Os segmentos nodais foram cortados com 1,0 cm de comprimento e individualizados em tubos de ensaio, com $10 \mathrm{ml}$ de meio de cultura. Os segmentos nodais foram cultivados in vitro, sob luz fluorescente com radiação de $20 \mathrm{mE} \cdot \mathrm{m}^{-2} \cdot \mathrm{s}^{-1}$, fotoperíodo de 16 horas e temperatura de $25 \pm 2^{\circ} \mathrm{C}$.

Nesta fase, avaliaram-se, após 35 dias, a percentagem de estabelecimento (\% de explantes que brotaram isentos de patógenos), contaminação e oxidação das cultivares estudadas. O delineamento experimental adotado foi o de blocos casualizados, com nove tratamentos e três repetições, sendo cada repetição constituída de cinco segmentos nodais. A comparação entre as médias dos tratamentos foi realizada pelo teste de Duncan $(a=0,05)$.

\footnotetext{
$\overline{1}$ (Trabalho 091/2002). Recebido:31/01/2002. Aceito para publicação:13/02/2003. Incluído no Projeto "Porta-enxertos para frutas de caroço", da FAEM/UFPel Embrapa Clima Temperado.

${ }^{2} \mathrm{Eng}^{\mathrm{O}} \mathrm{Agr}^{\mathrm{o}}$, Dr., CNPq, e-mail: rcale@ufpel.tche.br

${ }^{3} \mathrm{Eng}^{\mathrm{o}} \mathrm{Agr}^{\circ}$, M.Sc., FAEM/UFPel

${ }^{4} \mathrm{Eng}^{\mathrm{O}} \mathrm{Agr}^{\circ}$, Dr., Embrapa Clima Temperado; e-mail: gerson@cpact.embrapa.br; Cx. Postal 403, Pelotas/RS

${ }^{5} \mathrm{Eng}^{\mathrm{o}} \mathrm{Agr}^{\mathrm{o}}$, Dr., Prof. Titular FAEM/UFPel

${ }^{6} \mathrm{Eng}^{\mathrm{o}} \mathrm{Agr}^{\mathrm{o}}$, Livre Docente, Dr., Prof. Titular IFM/UFPel
} 


\section{Experimento II: Fase de multiplicação}

$\mathrm{Na}$ primeira fase de multiplicação, testaram-se os meios $\mathrm{SH}$ e MS 3/4, com as mesmas concentrações hormonais, vitaminas, ágar, açúcar e $\mathrm{pH}$ citados no estabelecimento. Utilizaram-se brotações inferiores a $0,5 \mathrm{~cm}$ de comprimento. Após 35 dias, avaliaram-se a taxa de multiplicação, calculada através da diferença entre o número final e o número inicial de gemas, dividido pelo número final multiplicado por 100; a percentagem de crescimento calculada pelo comprimento final e o inicial (medido com régua), expresso em percentagem, e o número de brotações obtido pela média do número final de brotações. As cultivares dos porta-enxertos em estudo foram: Mr.S 2/5, Mirabolano, Hansen 2168, Marianna Comum, Hansen 536, Okinawa, GF 677, Aldrighi e a cultivar copa Eldorado.

O delineamento experimental adotado foi o inteiramente casualizado, com o experimento fatorial A ( 9 cultivares) x B ( 2 meios de cultivo), com três repetições. Cada repetição constou de um frasco de $250 \mathrm{ml}$, com $30 \mathrm{ml}$ de meio e quatro explantes. A comparação entre as médias dos tratamentos foi realizada pelo teste de Duncan $(\mathrm{a}=0,05)$.

\section{Experimento III: Fase de multiplicação}

Na segunda multiplicação, após 35 dias, avaliaram-se as mesmas variáveis citadas no experimento II. As cultivares dos porta-enxertos em estudo foram: Marianna Comum, Mirabolano, Mr.S 2/5 e GF 677. Utilizouse o meio MS 3/4 com diferentes concentrações de ágar $(4,5 ; 5,5 ; 6,5$ g.L $\left.{ }^{1}\right)$, adicionado de $\operatorname{AIB}\left(0,05 \mathrm{mg} \cdot \mathrm{L}^{-1}\right), \operatorname{BAP}\left(0,6 \mathrm{mg} \cdot \mathrm{L}^{-1}\right)$ e $\mathrm{AG}_{3}\left(0,2 \mathrm{mg} \cdot \mathrm{L}^{-1}\right) . \mathrm{O}$ experimento foi um fatorial com quatro cultivares e três concentrações de ágar, sendo o delineamento inteiramente casualizado, com três repetições. As médias foram comparadas pelo teste de Duncan $(\mathrm{a}=0,05)$.

\section{RESULTADOS E DISCUSSÃO}

Experimento I: Os resultados do estabelecimento das cultivares podem ser observados na Figura 1. Esses resultados foram superiores àqueles obtidos por Rodrigues et al. (1999) que estabeleceram in vitro os porta-enxertos GF 677, Marianna Comum e Mirabolano. Essas diferenças podem ser atribuídas à época de coleta do material propagativo. As altas percentagens agora obtidas devem-se ao estado fisiológico da planta que, na época em que o material foi coletado (verão), se encontravam em pleno desenvolvimento vegetativo, enquanto, no trabalho desenvolvido por Rodrigues et al. (1999), as plantas de onde foram coletados os explantes, encontravam-se em início de dormência (outono). Esse fato provavelmente dificultou a circulação da seiva e de produtos sistêmicos, impedindo a desinfecção dos tecidos. Em função do que foi exposto, é importante observar a influência da época de coleta dos explantes sobre a capacidade de estabelecimento dos mesmos. Observou-se ainda que a maior percentagem de estabelecimento ocorreu no meio MS 3/4, não diferindo dos meios $\mathrm{SH}$ e MS (Figura 2). O meio Villegas proporcionou a menor percentagem de estabelecimento e número de explantes oxidados (Figura 2 e Tabela 2). Esse meio apresenta menor concentração de sais que os demais meios testados, o que influenciou na menor oxidação dos explantes.

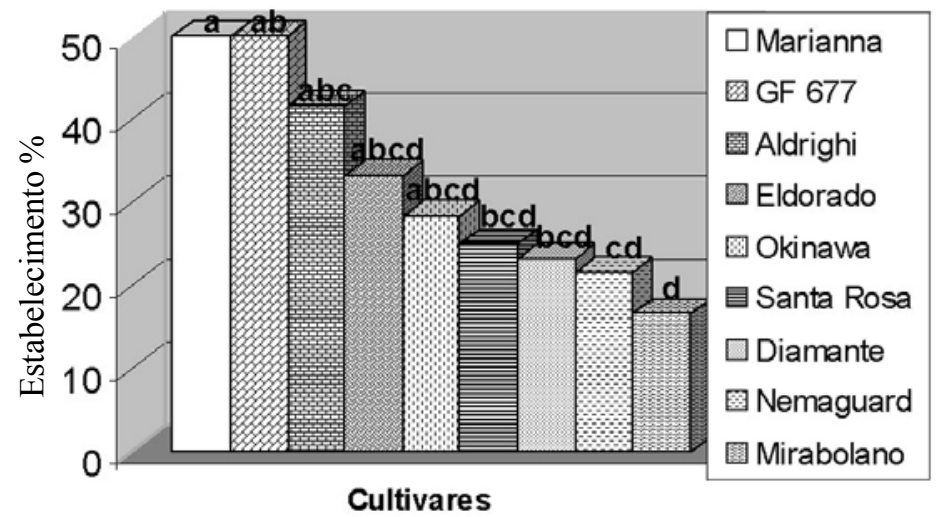

FIGURA 1- Percentagem de estabelecimento in vitro de nove cultivares de Prunus sp. Embrapa Clima Temperado. Pelotas-RS. 1999.

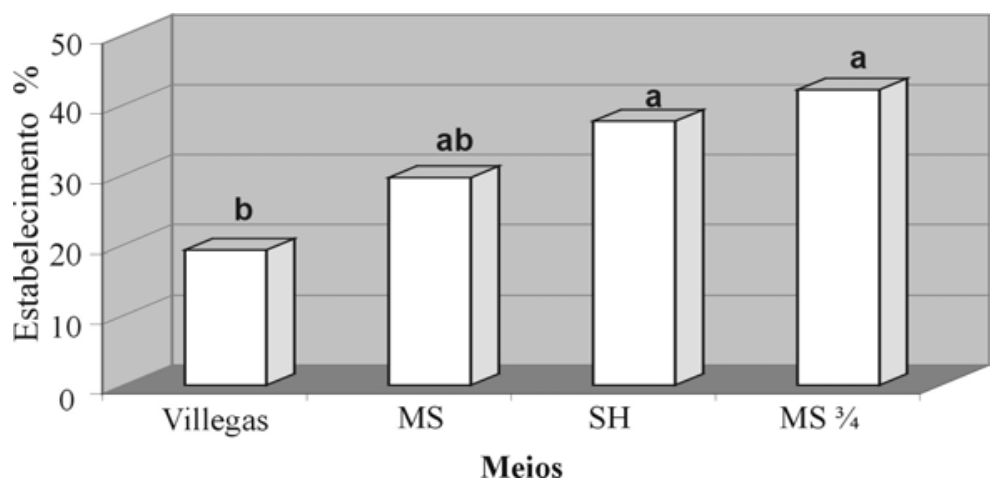

FIGURA 2- Percentagem de estabelecimento in vitro de Prunus sp. em quatro meios de cultivo. Embrapa Clima Temperado. PelotasRS, 1999.

As cultivares Mirabolano, Okinawa, Nemaguard, Diamante e Aldrighi apresentaram maior percentagem de contaminação, enquanto a cultivar Santa Rosa teve maior percentual de oxidação que as demais (Tabela 1). Segundo Rodrigues (2000), a cultivar Santa Rosa apresenta altas concentrações de compostos fenólicos totais. Os diferentes tipos de fenóis presentes nos tecidos, ao entrarem em contato com o oxigênio, sofrem reações de oxidação, cujos produtos resultantes são tóxicos, causando escurecimento e necrose do tecido vegetal. $\mathrm{O}$ uso de substâncias antioxidantes, tais como ácido ascórbico, PVP (polivinilpirrolidona), ácido cítrico e DIECA (dietilditiocarbamato), tem propiciado bons resultados no controle da oxidação no cultivo in vitro. Quanto à variação da percentagem de contaminação, no estabelecimento in vitro das diferentes cultivares em estudo, atribui-se às condições fitossanitárias do material vegetal coletado, visto que as plantas são mantidas em pomares e não sob condições controladas (telados e casas de vegetação).

TABELA 1-Percentagem de contaminação e oxidação dos segmentos nodais de nove cultivares de Prunus sp., na fase de estabelecimento in vitro. Embrapa Clima Temperado. Pelotas-RS.

\begin{tabular}{ccr}
\hline Cultivares & Contaminação \% & \multicolumn{2}{c}{ Oxidação \% } \\
\hline Mirabolano & $76,66 \mathrm{a}$ & $1,67 \mathrm{c}$ \\
Okinawa & $66,66 \mathrm{ab}$ & $3,33 \mathrm{bc}$ \\
Nemaguard & $63,33 \mathrm{abc}$ & $0,00 \mathrm{c}$ \\
Diamante & $58,33 \mathrm{abcd}$ & $11,67 \mathrm{bc}$ \\
Aldrighi & $50,00 \mathrm{abcd}$ & $3,33 \mathrm{bc}$ \\
Eldorado & $28,33 \mathrm{bcd}$ & $3,33 \mathrm{bc}$ \\
GF 677 & $21,66 \mathrm{bcd}$ & $16,67 \mathrm{~b}$ \\
Santa Rosa & $13,33 \mathrm{~cd}$ & $40,00 \mathrm{a}$ \\
Marianna Comum & $3,33 \mathrm{~d}$ & $11,66 \mathrm{bc}$ \\
\hline
\end{tabular}

Médias seguidas das mesmas letras não diferem entre si, pelo teste de Duncan $(\mathrm{a}=0,05)$

TABELA 2- Percentagem de segmentos nodais oxidados de nove cultivares de Prunus sp., em quatro meios diferentes, na fase de estabelecimento in vitro. Embrapa Clima Temperado. Pelotas-RS. 1999.

\begin{tabular}{cc}
\hline Meios & Oxidação \% \\
\hline MS & $13,3 \mathrm{a}$ \\
SH & $10,4 \mathrm{ab}$ \\
MS & $11,8 \mathrm{ab}$ \\
Villegas & $3,7 \mathrm{~b}$ \\
\hline
\end{tabular}

Experimento II: Em relação aos experimentos, na primeira fase de multiplicação, observou-se que o meio $\mathrm{MS} 3 / 4$ foi melhor do que o $\mathrm{SH}$ nas três variáveis (Tabela 3 ). O porta-enxerto Mr.S 2/5 apresentou a maior taxa de multiplicação, diferindo dos demais (Tabela 3), confirmando a performance deste porta-enxerto cultivado in vitro, conforme mostraram Theriou (1998) e Morini et al. (1990). Para as variáveis número de 
brotações e percentagem de crescimento, as cultivares Mirabolano e Mr.S 2/5 destacaram-se das demais (Tabela 3).

TABELA 3- Taxa de multiplicação, número de brotações e percentagem de crescimento dos explantes de nove cultivares de Prunus $s p$. multiplicadas in vitro, nos meios SH e MS 3/4. Embrapa Clima Temperado. Pelotas-RS. 1999.

\begin{tabular}{|c|c|c|c|}
\hline Meios & Taxa multiplicação & $\mathrm{N}^{0}$ de brotações & Crescimento \% \\
\hline MS 3/4 & $3,93 \mathrm{a}$ & $3,48 \mathrm{a}$ & $58,40 \mathrm{a}$ \\
\hline $\mathrm{SH}$ & $2,78 \mathrm{~b}$ & $2,84 \mathrm{~b}$ & $25,30 \mathrm{~b}$ \\
\hline Cultivares & & & \\
\hline Mr.S 2/5 & $6,12 \mathrm{a}$ & $5,91 \mathrm{a}$ & $82,10 \mathrm{ab}$ \\
\hline Mirabolano & $4,38 \mathrm{~b}$ & $6,93 \mathrm{a}$ & 104,73 a \\
\hline Hansen 2168 & $3,83 \mathrm{~b}$ & $2,72 \mathrm{bc}$ & $64,38 \mathrm{~b}$ \\
\hline Marianna Comum & 3,43 & $3,40 \quad b$ & $31,90 \mathrm{~cd}$ \\
\hline Hansen 536 & 3,32 bcd & $2,56 \mathrm{bc}$ & 58,53 bc \\
\hline Okinawa & 2,36 & $2,16 \quad \mathrm{c}$ & $7,47 \quad \mathrm{~d}$ \\
\hline GF 677 & 2,34 & 2,08 & 12,05 \\
\hline Eldorado & 2,24 & 2,08 & 11,97 \\
\hline Aldrighi & 2,12 & 2,00 & 3,48 \\
\hline
\end{tabular}

Médias seguidas das mesmas letras, nas colunas, não diferem entre si, pelo teste de Duncan $(a=0,05)$.

Experimento III: Na segunda fase de multiplicação, em que se avaliaram diferentes concentrações de ágar no meio MS 3/4, observou-se que a concentração de 5,5 g. $\mathrm{L}^{-1}$ propiciou maiores percentagens de crescimento, taxa de multiplicação e número de brotações (Tabela 4). Além dos diferentes meios básicos e fitorreguladores utilizados, a concentração de ágar também pode influenciar no cultivo in vitro. O ágar pode ser tóxico para algumas espécies, principalmente quando apresenta baixo grau de pureza (Caldas et al., 1990). Os explantes de Marianna Comum cresceram mais do que aqueles das cultivares Mirabolano e Mr.S 2/5, enquanto 'Mirabolano' apresentou maior taxa de multiplicação e número de brotações (Tabela 4). As percentagens de crescimento foram maiores do que as do primeiro experimento de multiplicação devido à utilização de $\mathrm{AG}_{3}\left(0,2 \mathrm{mg} . \mathrm{L}^{-1}\right)$ e maior concentração de $\mathrm{AIB}\left(0,05 \mathrm{mg} \cdot \mathrm{L}^{-1}\right)$.

TABELA 4- Taxa de multiplicação, número de brotações e percentagem de crescimento dos explantes de quatro cultivares de Prunus sp. multiplicadas in vitro, no meio MS 3/4, em três concentrações de ágar $\left(4,5 ; 5,5 ; 6,5\right.$ g.L $\left.\mathrm{L}^{-1}\right)$. Embrapa Clima Temperado. Pelotas-RS. 1999.

\begin{tabular}{lccc}
\hline $\begin{array}{c}\text { Concentração } \\
\left.\text { de ágar (g.L }{ }^{-1}\right)\end{array}$ & $\begin{array}{c}\text { Taxa de } \\
\text { multiplicação }\end{array}$ & $\begin{array}{c}\text { Número de } \\
\text { brotações }\end{array}$ & $\begin{array}{c}\text { \% de } \\
\text { crescimento }\end{array}$ \\
\hline 4,5 & $3,46 \mathrm{ab}$ & $4,13 \mathrm{ab}$ & $151,52 \mathrm{ab}$ \\
5,5 & $3,74 \mathrm{a}$ & $4,65 \mathrm{a}$ & $164,95 \mathrm{a}$ \\
6,5 & $2,97 \mathrm{~b}$ & $3,92 \mathrm{~b}$ & $120,44 \quad \mathrm{~b}$ \\
\hline Cultivares & & & \\
\hline Mirabolano & $4,98 \mathrm{a}$ & $5,78 \mathrm{a}$ & $161,80 \mathrm{~b}$ \\
Mr.S 2/5 & $3,24 \mathrm{~b}$ & $3,91 \mathrm{~b}$ & $133,12 \mathrm{~b}$ \\
GF 677 & $2,66 \mathrm{~b}$ & $2,10 \quad \mathrm{c}$ & $61,62 \quad \mathrm{c}$ \\
Marianna Comum & $2,66 \mathrm{~b}$ & $5,62 \mathrm{a}$ & $226,02 \mathrm{a}$ \\
\hline
\end{tabular}

Médias seguidas das mesmas letras, nas colunas, não diferem entre si, pelo teste de Duncan $(\mathrm{a}=0,05)$.

\section{CONCLUSÕES}

1) O meio Villegas proporciona menor percentual de oxidação dos explantes durante o período de estabelecimento in vitro.

2) Com o meio MS $3 / 4$, verificou-se maior percentagem de estabelecimento dos explantes de diferentes espécies do gênero Prunus.

3) Na multiplicação, o meio MS 3/4, contendo 5,5 g.L. $\mathrm{L}^{-1}$ de ágar, proporciona os melhores resultados para todas as variáveis estudadas.

\section{REFERÊNCIAS BIBLIOGRÁFICAS}

CALDAS, L.S.; HARIDASAN, P.; FERREIRA, M.E. Meios nutritivos. In: TORRES, A.C.; CALDAS, L.S. Técnicas e aplicações da cultura de tecidos de plantas. Brasília, ABCTP/EMBRAPACNPH, 1990, p.37-70.

GRATTAPAGLIA, D.; MACHADO, M. A. Micropropagação. In: Torres, A.C.; Caldas, L.S.; Buso, J.A. Cultura de tecidos e transformação genética de plantas. Brasília: Embrapa - SPI / Embrapa CNPH, 1998, p.183-260.

LORETI, F.; MASSAI, R. Portinnesti fruttiferi: Pesco. L'informatore Agrario, n.32, p.37-42, 1995.

MORINI S.; FORTUNA, P.; SCIUTTI, R.; MULEO, R. Effect of different light-dark cycles on growth of fruit tree shoots cultured in vitro. Advances in Horticultural Science, v.4, p.163-166, 1990.

MURASHIGE, T.; SKOOG, F. A revised medium for rapid growth and bioassays with tobacco tissue cultures. Physiologia Plantarum, Copenhagem, v. 15, p.473-497, 1962.

RODRIGUES, A.C.; FACHINELLO, J.C.; STRELOW, E.; FORTES, G.R.L. Estabelecimento in vitro de porta-enxertos de Prunus $s p$. Revista Brasileira de Fruticultura, Cruz das Almas, v.21, n.2, p.229-231, 1999.

RODRIGUES, A.C. Tese de Doutorado - Avaliação da compatibilidade da enxertia em Prunus sp. através de análises morfofisiológicas, níveis de fenóis e atividade da peroxidase. Pelotas: Faculdade de Agronomia Eliseu Maciel - Universidade Federal de Pelotas, 2000. 86p.

SCHENCK, R.U.; HILDEBRANDT, A.C. Medium and techniques for induction and growth of monocotyledonous and dicotyledonous plant cell cultures. Canadian Journal Botanica, Ottawa, v.50, p.199-204, 1972.

THERIOU, K. D. Response of increasing rates of $\mathrm{NaCl}$ or $\mathrm{CaCl}_{2}$ and proline on Mr.S. 2/5 (Prunus cerasifera) peach rootstock cultured in vitro. Advances in Horticultural Science, v.12, p.169174, 1998.

VILLEGAS, M.A.; BECERRIL, A.E.R.; AGUILAR, M.A.C. Respuesta in vitro de três cultivares de fresa a niveles de $\mathrm{NH}_{4} \mathrm{NO}_{3}$. In: CONGRESO NACIONAL DE FITOGENETICA, $\mathrm{n}^{\circ}$, 1992, Chiapas. 